\title{
Dam Break Wave Propagation on a Non- Erodible Bed - Comparison of Experimental and Numerical Results
}

\author{
Humna Hamid ${ }^{1}$,Fayaz Ahmad Khan ${ }^{2}$, Mujahid Khan ${ }^{3}$, Muhammad Ajmal ${ }^{4}$, Maria Mahmood, \\ Muhammad Sagheer Aslam ${ }^{2}$, Mohammad Tufail ${ }^{5}$ \\ ${ }^{1}$ Research Student, Master of Water Resources Engineering, Dept. of Civil Engineering, University of Engineering \& Technology, \\ Peshawar 25120, Pakistan \\ ${ }^{2}$ Assistant Professor, National Institute of Urban Infrastructure Planning, University of Engineering \& Technology, Peshawar \\ 25120, Pakistan \\ ${ }^{3}$ Associate Professor, Dept. of Civil Engineering, University of Engineering \& Technology, Peshawar 25120, Pakistan \\ ${ }^{4}$ Associate Professor, Dept. of Agricultural Engineering, University of Engineering \& Technology, Peshawar 25120, Pakistan \\ ${ }^{5}$ Consulting Engineer \\ Corresponding author: Fayaz Ahmad Khan (fayazuet@uetpeshawar.edu.pk)
}

\begin{abstract}
Dams are vital for production of electricity, storage of water and irrigation purposes but pose a serious risk to the community, if breached. The downstream flood wave propagation, resulting from failure of a dam can subject the population and infrastructure to considerable damage. No matter how low the chances of failure, the cost of failure makes it a higher risk. Mitigation of such risks requires better understanding of the hazard that a dam may pose in case of failure. This study focuses on the effects of flood wave propagation on a fixed bed on the downstream side resulting from sudden dam break. Two conditions are simulated: 1 . when the downstream side is open, 2 . when the downstream side is closed. It is observed that the flood wave diminishes in velocity and height with increase in time for both cases. For downstream open condition, the flood wave attains maximum height in 2 to $4 \mathrm{sec}$ and maximum velocity within 2 to $5 \mathrm{sec}$. For downstream closed condition, the flood wave attains maximum height within 5 to $10 \mathrm{sec}$ and maximum velocity within 3 to $5 \mathrm{sec}$. The results obtained from the twodimensional shallow water equation based numerical model are in close agreement with the experimental results.
\end{abstract}

Key words: Flood waves shallow water equation numerical model• dam break

\section{INTRODUCTION}

Flood wave propagation is one of the most crucial problems associated with a dam break. A flood is defined as a rising and overflowing of a body of water especially onto normally dry land[1].Flood wave propagation is a phenomenon in which waves of great depth and velocity propelled due to the kinematic energy. This sometimes result in the destruction of objects, infrastructure and human population present in its path. The severity of a dam break flood depends on the properties of the dam and the perennial inflow/outflow conditions (caused by glacier melts, rainfall etc.). Thus, each dam needs to be analyzed with its own set of conditions. Dam break analysis usually relates to the process of studying a dam failure phenomenon and analyzing the resulting consequences at the downstream region [2].

In majority of dam break analysis, the researchers have focused on the mechanism of dam break, dam breaching or channel topography [3], [4],[5],[6], [7], while few cases focused only on the flood wave downstream effects [8],[9].One such study was carried out on Urkmez dam (Turkey) to investigate the downstream damage caused by of sudden collapse. Snmall scale trapezoidal dam model was constrcuted in laboratory using using Froude's number similarity. A detailed depiction of real life conditions including highways and buildings were modeled to see the real effects of dam break. The conditions implemented were the change of elevation of water in reservoir for 5 cases with the $1^{\text {st }}$ case having the lowest water elevation and the 5th case having the highest.The water elevation in the channel is measured using GPS system with corresponding distances downstream of the reservoir. It was concluded that in case 5 with highest elevation in reservoir, the highest peak was observed and the wave is vanished in 70 minutes at a distance of $30 \mathrm{~km}$ with water easily passes through sparsely populated area and tends to retain in dense areas and takes time to move from there [10].

Some researchers studied the flood wave effects on mobile beds at the downstream side both in laboratory and as field experiments[11], [12]. In one study, a numerical model was developed using the most realistic real life conditions. Eight teams were invited to develop a numerical model based on a general framework of dam break wave propagation on a downstream sediment laden bed. Simulating the dam failure, scouring was observed in the dam nearest areas and deposition occurred on the extremities. Another study investigated the development of a 2D morphodynamic model for predicting dam-break flows over mobile beds modifying shallow water equations so that the evolution of the bed may be considered [13]. 
Humna Hamid et al., International Journal of Emerging Trends in Engineering Research, 9(6), June 2021, 733 - 740

The latest trend adopted these days is to study the effects of dam break flood waves through numerical model simulations [14]. One such study of numerical modeling is using shallow water equations concentrated on shallow water flow in two dimensions to carry out dam break tests [14], [15]. Numerical models based on partial differential equations are used in many other fields besides fluid flow simulations [16]. However, development of the numerical model depends on field data which is hard to obtain as dam break in real time is a sudden phenomenon and thus initial conditions, such as discharge, water level, and velocity etc. cannot be measured on the spot. In most cases, the numerical model considers the hydrodynamic conditions but neglects the impact on geomorphology. To overcome this difficulty, physical models are employed with preset conditions in a controlled environment and which help to determine the detailed and specific results using different instruments [11].Therefore, to validate results, the experimental models are compared to the numerical models.

From literature, it is evident that more attention is given to breach formation and downstream effects of a flood wave on mobile beds but studies of dam break on non-erodible beds, the effects of free-surface flows after dam break causing impact loads on structures like reservoir walls and the effects of temporary dam formations (debris dams) is even rarer which gives rise to the need of carrying out this research [18], [19]. Annually some regions in China face the formation of natural dams due to accumulation of debris. A study on the physical similitude of break of debris flow dam was carried out to address these situations [18]. These debris dams last for a short duration and then abruptly collapse causing damage to lives and infrastructure such as roads and buildings on the downstream side. The focus was on the mechanism that occurs to cause these dam breaks and the effect of dam failure on the downstream through modeling techniques. For this purpose, a model was developed on the basis of inertial geometric and Froude's number similarity with their corresponding scales. Once the scale models were developed, the procedure was carried out and the formation of debris dams as well as their failure was observed. The information was gathered from these series of experiments in which the dam width and the water depth etc. were changed and then used for the development of a numerical model. Numerous researchers have done work on dam break analysis using different hydraulic models. These studies are presented below.

HEC-RAS was used to simulate the dam break wave propagation using unsteady flow analysis. for Aparan dam in Armenia [20]. In this simulation, flood wave travel time, and discharge were calculated for two different conditions. It was concluded that flood wave velocity ranges from $4 \mathrm{~m} / \mathrm{s}$ for milder slope to $16 \mathrm{~m} / \mathrm{s}$ for steeper slope while the travel time was approximated as one hour. Similarly, for Foster Joseph Sayers Dam also HEC-RAS model was used [21]. It was noted that dam break analysis is a very complex phenomena involving number of principles, mechanics and procedures. It was concluded that there was not a significant impact on the height of flood wave however the nearby areas were greatly affected. To further refine the simulations, HEC-RAS with the river geometry derived from SRTM digital elevation model was used for dam break analysis [22]. In this study the inundation model was prepared by using HEC-Geo RAS and also the area inundated as well as the travel time were calculated.

A multipurpose rock fill dam named Fincha'a having number of important infrastructures on its downstream was analyzed using HEC-RAS [23]. Center of the dam was assumed to be the dam break location spreading equally in both sides. It was concluded that dam failure due to overtopping was more severe as compared to the one caused by piping. In the same way Parwana dam analysis was done using HEC-RAS with the aim to find out number of villages affected and amount of submergence area [24]. It was concluded that dam break investigation is very useful for proper planning of the flood wave downstream of dam.

Besides HEC-RAS, some researchers have used other models for dam break analysis. One such example is Dam Break Analysis of Thenmala Dam, India using BOSS DAMBRK software to investigate, extent of inundation, flood wave travel time and velocity [25]. Maximum precipitation was evaluated using Gunmel's method while maximum flood was calculated using Clark's method. Another similar study was carried out for Machhu dam II in which investigation was done using NWS-DAMBRK in (1990), MIKE11 in (2008) and HEC-RAS in (2008) and results were compared [26]. It was concluded that MIKE 11 results were closer to the observed values. Similarly, DAMBRK results in very high inundation of downstream region, followed by HEC-RAS while MIKE 11 gave the minimum inundation.

Dam Break flood inundation mapping was done using GIS integrated hydrological modeling. MIKE 21 software was used for such mapping[27]. The analysis provides scientific management plan in case of emergency and also a socioeconomic framework.

It is worth mentioning that there is still need to carryout research for finding the water surface profile and time of travel for wave propagation due to dam break. Similarly, majority of the studies analyzed the partial dam breaks considering only the dam break wave propagation without any obstruction on the downstream. The objectives of the current study are to investigate the dam break downstream wave propagation using experimental and numerical approaches and considering the longitudinal and cross-sectional profile of propagated wave [28]. Additionally, the dam break downstream wave propagation analysis is carried out for two different conditions including 1. downstream open (without obstruction), and 2. downstream closed (with obstruction). These three points make this research different than the previously presented research i.e. full dam break, downstream open as well as close condition and use of shallow water equation based new numerical model with hope to find accurate investigation of the phenomena. 


\section{MATERIALS AND METHODS}

In order to simulate real life conditions of dam break flood wave propagation, physical models are used in controlled environments with pre-set conditions. These models may be small scale (in the laboratory) or large scale (in the field) depending on budget and space availability. The parameters and conditions are pre-defined as compared to the real time phenomena of dam break and instruments are used for precise required data measurements.

To physically model the downstream flood wave propagation profile and time of travel, the following experimental setup was arranged in the hydraulic laboratory of Civil Engineering Department, University of Engineering and Technology Peshawar, Pakistan.

\subsection{Experimental Setup}

\subsubsection{Open channel}

The experiments were carried out in an open channel of the Hydraulics Laboratory as shown in (Fig. 1). The channel is made of steel frames and a glass body for visual observations. The length of the channel is $6.75 \mathrm{~m}$ (22.0 feet) with a slope of 0.002 . Its width and height are $0.3048 \mathrm{~m}$ (1.0 foot) and $0.762 \mathrm{~m}$ (2.5 feet) respectively. The channel two gates one at the upstream (U/s) and other at the downstream (D/s) were operated manually. It was attached to a tank or reservoir on the $\mathrm{U} / \mathrm{s}$ by means of a small converging flume (considered as the dam) for the experiments.

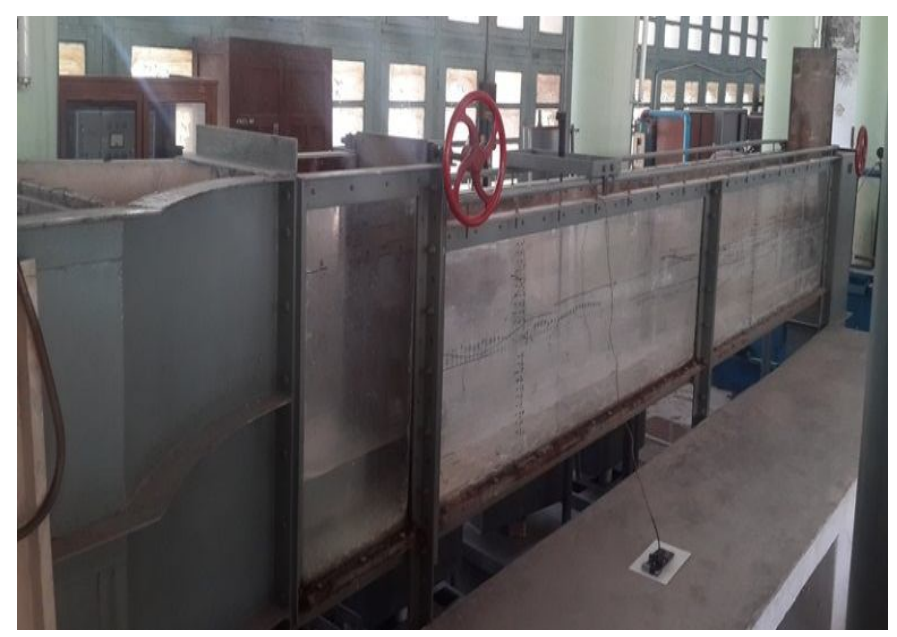

Fig. 1Open Flow Channel with reservoir

\subsubsection{Velocity Sensor}

A standard scale marked on channel was used to measure the height of the wave at different sections of the channel and a velocity sensor was especially designed to record the velocity of the flood wave. It was prepared by attaching a flow rate sensor with an Arduino chip. The flow rate sensor has a wheel inside the plastic body which is forced into motion because of the flood wave. A small magnetic clip was attached to the body of the sensor which encounters the vanes of the wheels and records the data in revolutions per second. This data is then transmitted by means of pulses and wires attached to the sensor and the Arduino chip. The data is then converted into meter per minute $(\mathrm{m} / \mathrm{min})$ through programming and the reading is observed on the display interface (Fig. 2).

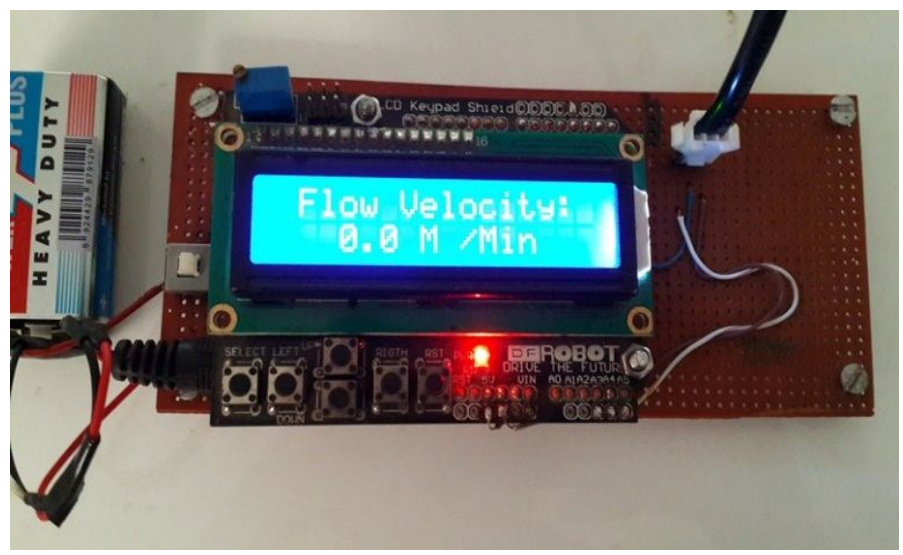

Fig. 2Velocity Sensor for flow velocity measurement

\subsection{Experimental Procedure}

The tank attached to the channel was fist filled up to about $0.9 \mathrm{~m}$ height with water from underground water tank keeping the downstream gate of reservoir closed. To start the experiment, the gate of the reservoir was opened manually to simulate the dam break. With sudden opening of the gate, a strong flood wave propagating towards the downstream channel is generated. The data (height, velocity) was collected by means of point gauge and scale placed at fixed intervals of $0.127 \mathrm{~m}$.

For each condition, the velocity sensor and ruler were placed at 340 sections. At every section, the flood wave velocity and height were measured using the same procedure to ensure uniformity and minimize error in the data collection. The control sections were taken at $0.127 \mathrm{~m}$ intervals along the length of the channel $(\mathrm{X})$ and at two points $0.1524 \mathrm{~m}$ and $0.2032 \mathrm{~m}$ along the width (Y) of the channel respectively.

The sensor was placed at a height equal to the height where average velocity could be measured which was approximately calculated as $0.1016 \mathrm{~m}(\mathrm{Z})$. (Average flow velocity for shallow water flow is at $0.6 \times \mathrm{H})$. The measurements were recorded continuously for both conditions but the time of recording for varied as follows:

- For D/s open condition, the time taken for data measurement was $42 \mathrm{sec}$ as this is equal to the time taken by the flood wave to completely dissipate.

- For D/s closed condition, the time taken for data measurement was $92 \mathrm{sec}$ as this is equal to the time taken by the flood wave to become still at a continuous height approximately.

The data taken at each cross section was then plotted to observe velocity and height variation. The same data was then used for numerical simulation as well. At the end, the experimental results were compared to the results obtained 
from numerical model which is based on two-dimensional shallow water equation.

\section{RESULTS}

After carrying out the experimental analysis, the results were obtained for depth of flow as well as flow velocity at different sections along the length and width of the channel as discussed above. The result obtained will be discussed in detail in the following section.

\subsection{Height variation of flood wave propagated due to dam break for downstream gate open condition}

The maximum height of propagating wave recorded at different sections along the channel length for downstream gate open condition is shown in Table 1. The results depicted that with the passage of time, the maximum wave height decreased because of the reduction in reservoir water level. Similarly, with the increase in distance from the dam downstream, the maximum wave height also decreases. From experimental analyses, the variation in flood wave height measured at different sections along the channel is shown in Fig. 3. It shows that the wave height decreases with the passage of time at all sections. It was also observed that the peak wave height at all sections occurred during the first 6 seconds and after that it started decreasing.

Table 1 Maximum height variation of flood wave with time along different channel section for downstream gate open condition

\begin{tabular}{|c|c|c|c|c|c|c|}
\hline $\mathrm{X}(\mathrm{m})$ & 1.016 & 1.270 & 1.651 & 2.794 & 3.556 & 4.445 \\
\hline $\begin{array}{c}\text { Max. H } \\
(\mathrm{m})\end{array}$ & 0.3810 & 0.3556 & 0.3175 & 0.2667 & 0.2540 & 0.2476 \\
\hline T (sec) & 1 & 2 & 3 & 4 & 5 & 6 \\
\hline
\end{tabular}

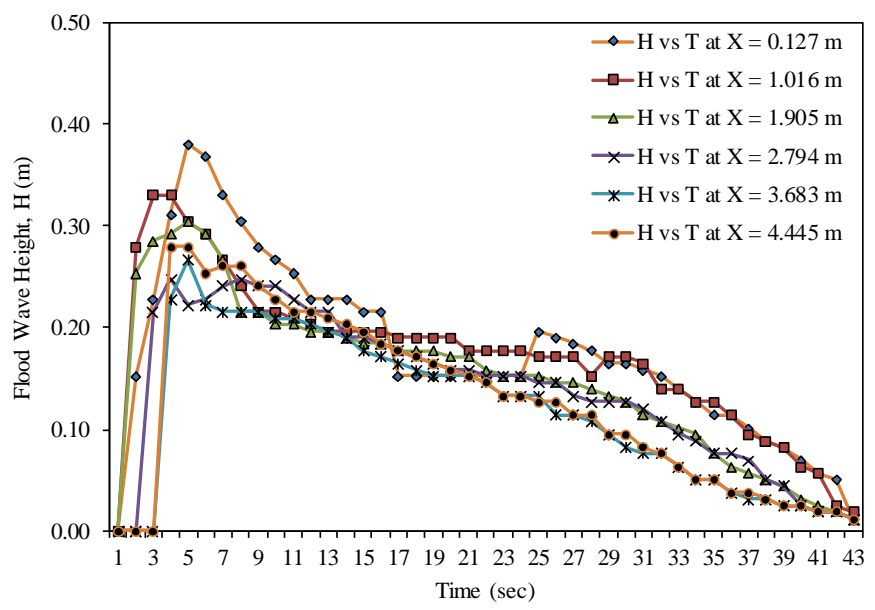

Fig. 3 Variation of flood wave height with time at different channel sections for $\mathrm{d} / \mathrm{s}$ gate open condition

\subsection{Height variation of flood wave propagated due to dam break for downstream gate closed condition}

The maximum height variation with time along channel section recorded for the downstream gate closed condition (with obstruction) is shown in Table 2. Results showed that the maximum height attained by the flood wave occurs from 4 to $10 \mathrm{sec}$ of dam break. The dam heights in Table 2 are much higher than the wave heights shown in Table 1. The reason is that in close gate condition, flood wave is propagated back towards the dam after hitting the downstream closed gate resulting in more wave height as compared to open gate condition. Similarly, the time taken by the wave to generate maximum height is also more in this case because water fluctuates between the two gates and took much time to attain maximum height. The detailed data obtained from the experimental analysis is shown in Fig. 4. It shows that after reaching the peak value, the wave height is not continually decreasing rather it becomes constant after some time. It is again due to downstream closed gate which is not allowing the water to discharge from the channel.

Table 2 Maximum height variation of flood wave with time along different channel section for downstream gate close condition

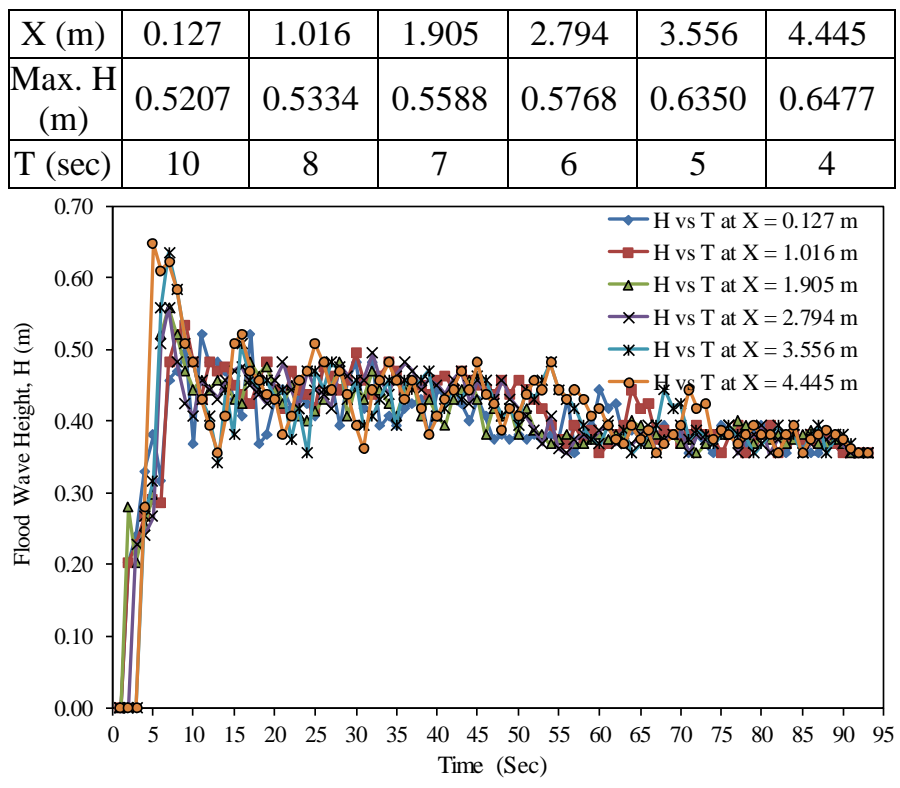

Fig. 3Variation of flood wave height with time at different channel sections for $\mathrm{d} / \mathrm{s}$ gate closed condition

\subsection{Velocity variation of flood wave propagating downstream due to dam break for $d / s$ gate open condition}

The maximum velocity recorded for a selected number of cross sections when the flood wave travels downstream without any obstructions i.e., downstream gate open condition is shown in Table 3 . The maximum velocity attained by the flood wave occurs from 1 to $6 \mathrm{sec}$ of dam break along different channel sections. It was also noted that maximum of all velocities occurs at the section nearest to the dam break point. Results from experimental analysis are shown in Fig. 5. From this 
figure, it is also justified that the velocity is maximum in first few seconds and then deceased.

Table 3 Maximum velocity variation of flood wave with time along different channel section for downstream gate open condition

\begin{tabular}{|l|c|c|c|c|c|c|}
\hline $\mathrm{X}(\mathrm{m})$ & 1.016 & 1.27 & 1.651 & 2.794 & 3.556 & 4.445 \\
\hline $\begin{array}{l}\text { Max. } \\
\text { Velocity } \\
(\mathrm{m} / \mathrm{s})\end{array}$ & 5.5512 & 5.4117 & 5.1600 & 5.0760 & 4.7450 & 4.4950 \\
\hline $\mathrm{T}(\mathrm{sec})$ & 1 & 2 & 3 & 4 & 5 & 6 \\
\hline
\end{tabular}

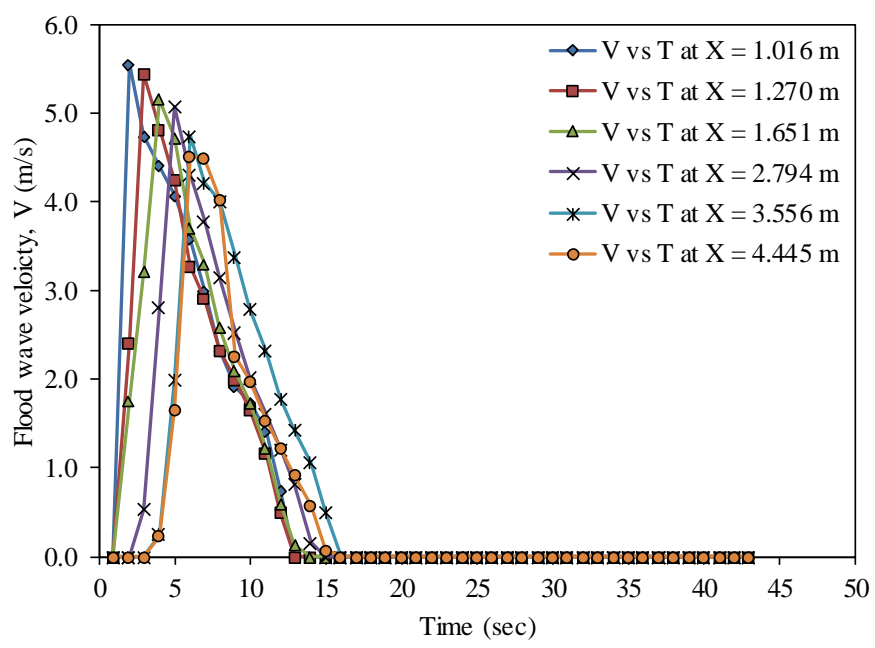

Fig. 4Variation of flood wave velocity with time at different channel sections for $\mathrm{d} / \mathrm{s}$ gate open condition

\subsection{Velocity variation of flood wave propagating downstream due to dam break for $\mathrm{d} / \mathrm{s}$ gate close case}

The maximum velocity variation recorded for a selected number of cross sections when the flood wave travels downstream for the $\mathrm{d} / \mathrm{s}$ gate closed condition (with obstructions) is shown in Table 4. The results show that the maximum velocity attained by the flood wave occurs from 2 to $6 \mathrm{sec}$ of dam break with maximum at the nearest section. This is because of the downstream gate closed condition although the flood wave is bounced back by the close gate but with velocity smaller than it had at the initial time. Therefore, variation pattern is different than shown Table 2 for maximum height variation in the same case. The results obtained from the experimental analysis are shown in Fig. 6. It is evident that with the passage of time, the velocity is reduced until it approaches zero.

Table 4 Maximum velocity variation of flood wave with time along different channel section for downstream gate close condition

\begin{tabular}{|l|c|c|c|c|c|c|}
\hline $\mathrm{X}(\mathrm{m})$ & 0.127 & 1.016 & 1.905 & 2.794 & 3.556 & 4.445 \\
\hline $\begin{array}{l}\text { Max. } \\
\text { Velocity } \\
\text { V } \\
(\mathrm{m} / \mathrm{sec})\end{array}$ & 4.9951 & 4.9118 & 4.8284 & 3.556 & 3.2467 & 0.3317 \\
\hline $\mathrm{T}(\mathrm{sec})$ & 1 & 2 & 3 & 4 & 5 & 6 \\
\hline
\end{tabular}

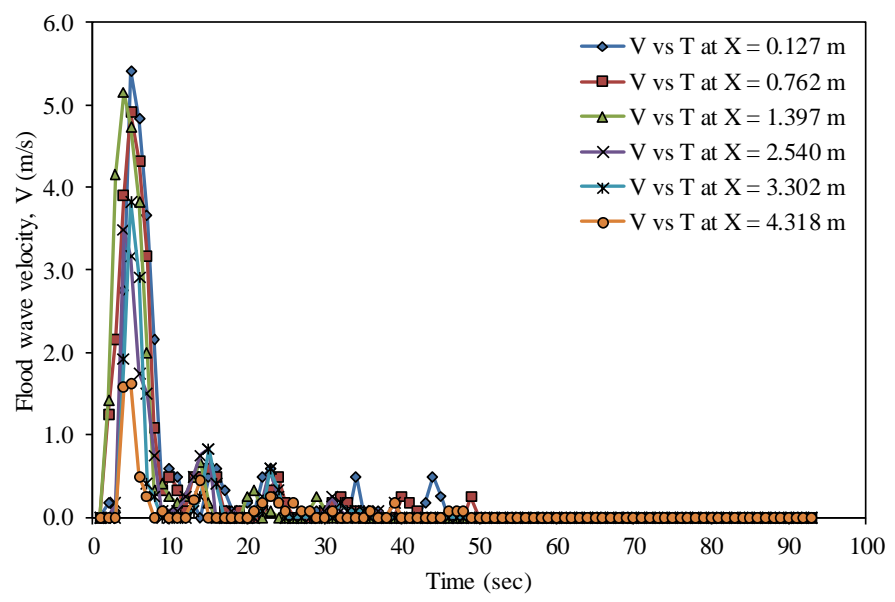

Fig. 5Variation of flood wave velocity with time at different channel sections for $\mathrm{d} / \mathrm{s}$ gate close condition

\subsection{Numerical Simulations of dam break}

To compare results obtained from experimental analysis, the numerical simulations for dam break are carried out through a numerical model, based on two-dimensional shallow water equations. This model solves shallow water equations using high resolution shock capturing techniques based on irregular triangular mesh. Simulations are done using ROE solver and MGM limiter [18]. Data pre-processing [12] was accomplished using Argus software for the downstream closed condition (with obstruction) only. Different dimensions and shape, layers, parameters and initial conditions of the channel and reservoir were defined which were required as input for the numerical model. The simulation was then carried out by the numerical model.

The output file generated water surface elevation $(\eta)$, bed elevation, $h_{u}, h_{v}$. The height and velocity variation were derived from the data by using the following expressions:

$$
h=\eta-\text { Bed elevation }
$$

Where $\boldsymbol{\eta}=$ water surface elevation, $\mathrm{h}=$ height of water in channel and $\mathrm{V}=$ velocity of water in channel.

$$
V=\sqrt{u^{2}+v^{2}}
$$

Where, $\mathrm{u}$ is component of velocity in $\mathrm{x}$ direction and $\mathrm{v}$ velocity component in y (lateral direction) and are given by

$$
u=\frac{h_{u}}{h} \quad \text { and } \quad v=\frac{h v}{h}
$$

\subsection{Experimental and Numerical velocity Results Comparison for $\mathrm{d} / \mathrm{s}$ dam close condition}

The results obtained from numerical model and converting using the above equation was then plotted against the channel length for different timings and was compared with experimentally observed data. The data obtained is shown in Fig. 7, 8 and 9 for 3, 4, and 5 seconds time respectively. The results show very close relation in all three figures with respect to the maximum velocity values, but it was observed that 
experimental peak velocity is lagging behind the numerical peak velocity by 1 or 2 seconds. The reason behind this delay is the time required to manually open the reservoir gate representing dam break.

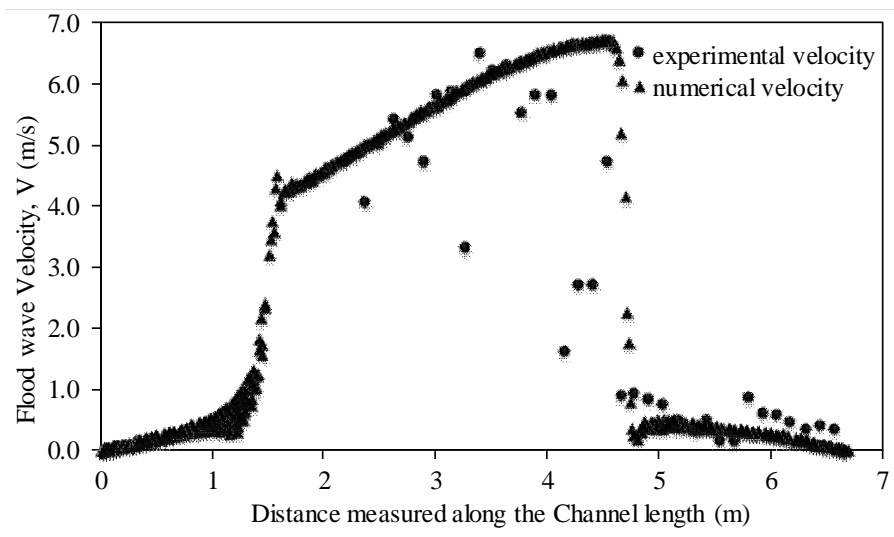

Fig. 6 Comparison of numerical and experimental flood wave velocity for $\mathrm{d} / \mathrm{s}$ closed condition at time $=3 \mathrm{sec}$

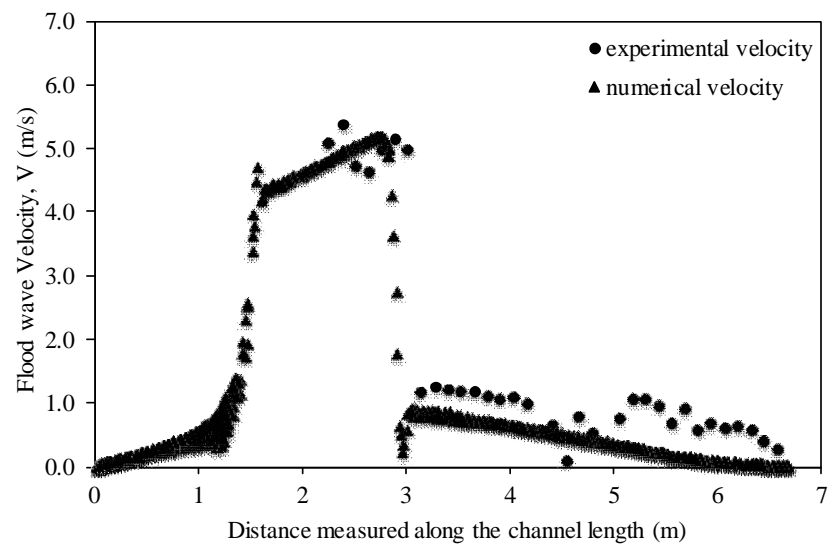

Fig. 7 Comparison of numerical and experimental flood wave velocity for $\mathrm{d} / \mathrm{s}$ closed condition at time $=4 \mathrm{sec}$

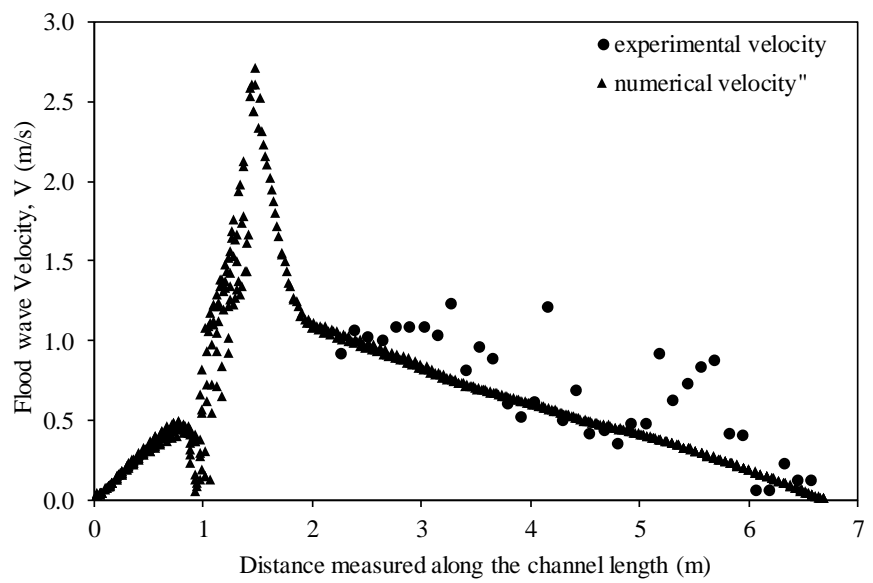

Fig. 8 Comparison of numerical and experimental flood wave velocity for $\mathrm{d} / \mathrm{s}$ closed condition at time $=5 \mathrm{sec}$

\subsection{Experimental and Numerical Results Comparison for Wave Height}

Just like velocity of flood wave, the height was also measured from numerical simulation of dam break phenomena and the results were compared with the experimental results. These comparisons are shown in Fig. 10, 11 and 12 corresponding to 6,8 , and 10 seconds time respectively. Fig. 10 shows the numerical flood wave moving in forward direction while in Fig. 11 and 12, the numerical wave is the reverse wave moving towards the dam after hitting the downstream close gate/obstruction. Similarly, for flood wave height along the channel length both numerical and experimental results are in close agreement with one another. However experimental values were found slightly greater than numerical one. There was only one difference between the numerical and experimental results as the location of maximum wave height. Just like velocity, maximum height for experimental results was also lagging the numerical maximum values because of the same reason as discussed above.

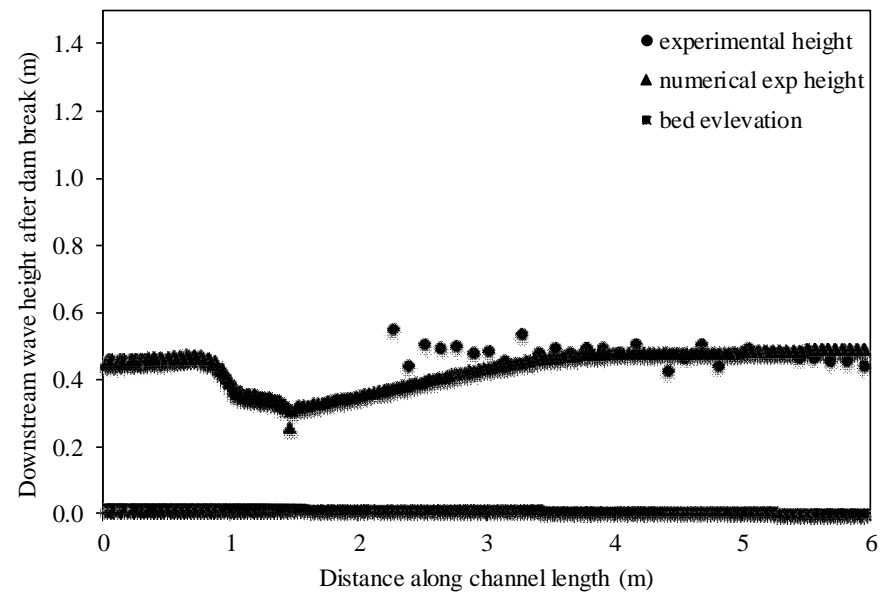

Fig. 9 Comparison of numerical and experimental flood wave height for $\mathrm{d} / \mathrm{s}$ closed condition at time $=6 \mathrm{sec}$

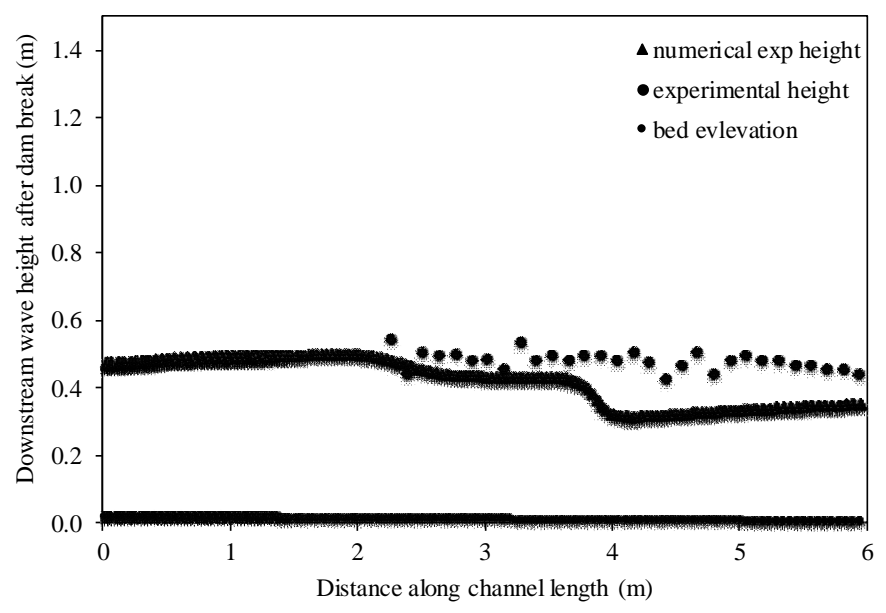

Fig. 10 Comparison of numerical and experimental flood wave height for $\mathrm{d} / \mathrm{s}$ closed condition at time $=8 \mathrm{sec}$ 


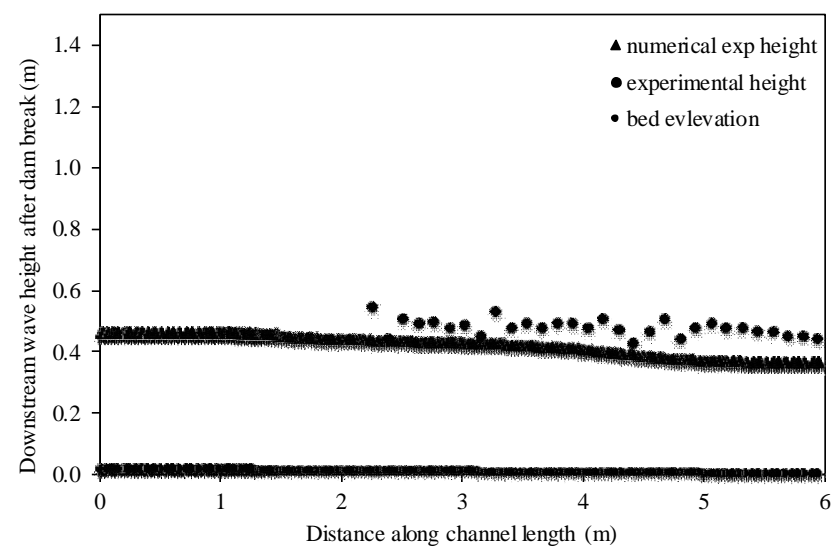

Fig. 11Comparison of numerical and experimental flood wave height variation for $\mathrm{d} / \mathrm{s}$ closed condition at time $=10 \mathrm{sec}$

\section{CONCLUSIONS}

The findings of this study can be concluded as:

1 Experimentally, $\mathrm{d} / \mathrm{s}$ gate close condition generated more wave height as compared to $\mathrm{d} / \mathrm{s}$ open gate condition due to back water effect of wave coming back after hitting the $\mathrm{d} / \mathrm{s}$ gate and water accumulation. Similarly, in earlier case, velocity is much lower as compared to the latter case.

2 For flood wave height analysis, it is concluded that $\mathrm{d} / \mathrm{s}$ gate close condition will generate maximum height of flood wave which can inundate surrounding area more as compared to $\mathrm{d} / \mathrm{s}$ gate open condition as it generate lesser heights. Contrarily, for $\mathrm{d} / \mathrm{s}$ gate close condition, wave height will take more time to reach to the peak as compared to $\mathrm{d} / \mathrm{s}$ gate open condition. So, in case there is any obstruction produced by the sediments resulted from dam break then the flood wave will attain more height and will cause inundation of surrounding areas. Consequently, community will be affected to evacuate the nearby areas, however the wave height will be attained slowly, and the authorities will have a bit more time to execute evacuation plan. But in case of no obstruction, the wave height will be lower extending to more inundated area.

3 Based on comparison of numerical and experimental results, it is concluded that both shows very close results and the slight deficiency can be reduced by making improved arrangements for experimental analysis.

\section{RECOMMENDATIONS}

In order to obtain accurate results, the apparatus used for modeling may be constructed with tight sealing to ensure no leakage and to conserve the mass of water in the reservoir and channel. Similarly, the gate used may be electronically operated to ensure minimum time and to avoid lagging of experimental waves. Similarly, instead of using a single velocity sensor, a sensor may be developed to measure velocity continuously along the channel length for precise measurements. In addition, beside conducting tests for wave height and flow velocity variation measurementsand flood wave propagation on a fixed bed, research may be carried out for specific dams considering the exact geomorphic conditions in the reservoir and channel.

\section{REFERENCES}

1. Yevjevich V (1994) Floods and society, In: Coping with floods. Springer, Dordrecht 3-9

2. Pandya HP, Jitaji TD (2013) A brief review of method available for dam. Paripex.-Indian J Res 2(4): 117-118

3. Wahl TL (2010) Dam breach modeling - an overview of analysis methods. Joint Federal Interagency Conference on Sedimentation and Hydrologic Modeling, June 27 - July 1, 2010

4. Wahl TL (2004) Uncertainty of Predictions of Embankment Dam. J Hydraul Eng 130(5): 389-397

5. Mohamed AAM, Samuels GP, Morris WM, Ghataora SG (2001) Modelling Breach Formation through Embankments. Wallingford Howbery Park, Wallingford, Oxon, OX10 8BA, UK School of Civil Engineering, The University of Birmingham, Edgbaston, B15 2TT, U.K

6. Hassan MAA, Morris MW, Hanson G, Lakhal K Breach formation: Laboratory and numerical modelling of breach formation. Association of State Dam Safety Officials: Dam safety Pheonix, Arizona

7. Ozmen-Cagatey H, Kocaman S (2011) Dam-break flow in the presence of obstacle: experiment and CFD simulation. J Eng Appl Comput Fluid Mech 5(4): 541552

8. Frazao SS, Zech Y (2007) Experiments of dam break flow against an isolated obstacle. J Hydraul Res 45: 27-36

9. Tayfur G, Guney MS(2013)A physical model to study dam failure flood propagation. Water Utility J6: 19-27

10. Bashar KEE, Khudair BH, Khalid GK(2014) Large scale field physical model simulation of roseires dambreak, Sudan. J Water Res Hydraul Eng 3(2): 48-56

11. Soares-Frazão S, Canelas R, CaoZ, CeaL, ChaudhryHM, MoranAD(2012) Dam-break flows over mobile beds: experiments and benchmark tests for numerical models. J Hydraul Res50: 364-375

12. Spinewine B, ZechY(2007) Small-scale laboratory dam-break waves on movable beds. J Hydraul Res45: $73-86$

13. Xia J,Lin B,Falconer RA, Wang G (2010) Modelling dam-break flows over mobile beds using a 2D coupled approach. Adv Water Res 33(2):171-183

14. Khan FA, Hamid H, Badrashi YI (2021) TwoDimensional Hydrodynamic Erosion Model Applied to Spur Dykes, Journal of Mechanics of Continua and Mathematical Sciences, Vol. 16, Issue 2, 22-34

15. Brufau P, Garcia $\square$ Navarro P (2000) Two $\square$ dimensional dam break flow simulation. Int $\mathbf{J}$ Num Meth Fluids 33(1): 35-57

16. Khan MU, Saeed S, Khan FA, Aslam MS, Badrashi YI (2021) Study of the Response of PW Traffic Flow Model to a Bottleneck on a Circular Road and its Suitability for Heterogeneous Traffic Conditions, International Journal of Emerging Trends in Engineering Research, Vol. 9, Issue No. 4, 460 -463

17. Zoppou C, Roberts S (2000) Numerical solution of the two-dimensional unsteady dam break. App Math Model 24(7): 457-475 
Humna Hamid et al., International Journal of Emerging Trends in Engineering Research, 9(6), June 2021, 733 - 740

18. Cheng Z, Xueyoung G, Chao D, Jingjing L (2007) Modeling experiment of break of debris-flow dam. Wuhan Uni J Nat Sci 12(4): 588-594

19. Parvathy GP, Goel A, Iyer HR(2015) Numerical modeling of advancing wave front in dam break problem by incompressible Navier-stokes solver. International Conference on Water Resources, Coastal and Ocean Engineering (ICWRCOE 2015) Aquatic Procedia 4, 861-867

20. Bjerke PL (2011)Dam Break Analysis for Aparan Reservoir, Armenia, Norwegian Water Resources and Energy Directorate, Middelthunsgate 29, P.O. Box 5091 Majorstua, N 0301 OSLO, NORWAY

21. Xiong Y (2011)A Dam Break Analysis Using HECRAS.J Water Resour Prot 3: 370-379

22. Chandrabose G, Nair BT(2014) Dam break analysis using HEC-RAS with DEM generated Geometry. International Journal of Scientific \& Engineering Research 5(7): 313-319

23. Duressa JN, Jubir AK(2018) Dam Break Analysis and Inundation Mapping, Case Study of Fincha'a Dam in Horro Guduru Wollega Zone, Oromia Region. Ethiopia Science Research 6(2): 29-38

24. Kulkarni SR, Jagtap SA(2017) Dam Break Analysis of Pawana Dam. International Journal of Recent Advances in Engineering \& Technology 5(1):20-23

25. George AC, Nair BT(2015) Dam Break Analysis Using BOSS DAMBRK, Aquatic Procedia 4:853 860

26. Aravind V, Perumal M, Rai NN (2017) Performance evaluation of three Dam failure analysis models, Third National Dam Safety Conference IIT Roorkee 1819February 2017

27. Mao J, Wang S, Ni J, Xi CWJ(2017) Management System for Dam-Break Hazard Mapping in a Complex Basin Environment ISPRS. Int J Geo-Inf 6(162): 1-14

28. Khan FA (2010) Two-dimensional shock capturing numerical simulation of shallow water flow applied to dam break analysis. Doctoral dissertation, Department of Architecture, Building and Engineering, Loughborough University, UK 